\title{
Factors affecting adoption behavior for Tablet device among computer users in Pakistan
}

\author{
Rafique Ahmed Khuhro ${ }^{a^{*}}$, Qasim Ali Qureshi ${ }^{b}$, Asad Afzal Humayon ${ }^{c}$, Samia Tahir ${ }^{d}$ and Asad Khan ${ }^{e}$
}

\author{
${ }^{a}$ Assistant Professor at University of Haripur, Department of Management Sciences, University of Haripur, Hattar Road, Haripur, Pakistan \\ ${ }^{b}$ Lecturer at CIIT Vehari, Department of Management Sciences, CIIT Vehari, Peer Murad, Vehari, Pakistan \\ ${ }^{c}$ Assistant Professor at CIIT Vehari, Department of Management Sciences, CIIT Vehari, Peer Murad, Vehari, Pakistan \\ ${ }^{d}$ Lecturer at CIIT Vehari, Department of Management Sciences, CIIT Vehari, Peer Murad, Vehari, Pakistan \\ ${ }^{e}$ Lecturer at University of Haripur, Department of Management Sciences, University of Haripur, Hattar Road, Haripur, Pakistan

\section{CH R O N C L E A B S T R A C T}

Article history:

Received June 5, 2016

Received in revised format

October 2, 2016

Accepted November 2, 2016

Available online

November 9, 2016

Keywords:

Adoption behavior

Tablet device

TAM model

Facilitation condition

Perceived price

Perceived ease of use

Perceived usefulness

Attitude

\begin{abstract}
Mobile computing represents a need of this decade. Mobile computing is possible with a tablet device, for which there is no clear-cut definition. It is partly because mobile computation field is still an emerging field. Tablet industry is still in its infancy stage and therefore, standards have yet to be defined. Given the limitations, however, a tablet device can be defined as a computing device smaller and slower than a laptop, however larger, and faster than a palm type device. In this research work, factors affecting adoption behavior for tablet device among computer users have been studied. An integral part of the study was to compare effect of the income level on adoption behavior. In this regard, two samples of private and public university students were studied. A modified technology acceptance model (TAM) has been used. Two variables were added to TAM model based on Pakistan's demographics. A questionnaire was used to collect data. 1000 questionnaires were distributed from which we received 972; twenty two questionnaires were having major missing values so they were separated from analysis. Twenty five respondents were found outliers during data screening; by this sample used in this study is 925. Results were analyzed using linear regression which showed only perceived ease of use and perceived usefulness affected attitude to adopt tablet device. These results were found to be consistent for both private and public universities. Facilitation conditions and price perception play an insignificant role. The results confirmed perceived usefulness and ease of use are the only important factors affecting adoption behavior for tablet device.
\end{abstract}

\section{Introduction}

Mobile computing represents a need of this decade. Mobile computing is possible with a tablet device, for which there is no clear-cut definition. It is partly because mobile computation field is still an emerging field. Tablet industry is still in its infancy stage and therefore, standards have yet to be defined. Given the limitations, however, a tablet device can be defined as a computing device smaller and slower than a laptop, however larger, and faster than a palm type device.

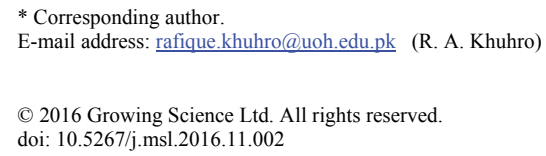


The main specialty of a tablet device is to provide functionality of mobile computing, which is otherwise not possible through palm size mobile device or Smartphone. Earlier tablets were pen based; however, presently tablet devices are touch sensitive to fingers as well (McClard \& Somers, 2000). The most commonly known tablet device is the Apple's Ipad.

Numerous research studies have been conducted on consumer behavior related to smart phones, mp4 players, e-readers, Tablet PC's, and Ipads in an international context. Tablet devices constitute the latest trend in mobile computing with mobility as their main aspect, followed by mobile communication. Windows XP based tablet devices were launched way back in 2002. However, they failed to impress masses because of lack of mobile communication capabilities and non-detachable keyboard. A recent study on tablet devices is by Anderson et al. (2006). It was found consumer give significant importance to performance expectancy and voluntariness.

As mentioned above, the most popular tablet in the world is the Apple's Ipad. 15 million Ipad were sold in first 11 months of its debut (Henderson \& Yeow, 2012). Although tablet PC's have existed since the sixties in one form or another, however, they were not user friendly (Halme, 2011). For example, earlier tablets had touch input through a touch pad device similar to touch pad on laptops, the only difference being stylus could be used to annotate on documents visible on screen. Apple's tablet referred to as Ipad is truly a mobile computing device excellent for mobile viewing of songs, movies, word processing and/or graphic designing. All tablet devices have internet connectivity through WIFI or GSM technology. GSM has an added advantage of providing mobile connectivity everywhere. Latest tablets have moved to the $4 \mathrm{~g}$ technology. With integration of mobile connectivity and WIFI technology in a single device that is as capable as a laptop and as compact as a Smartphone, a revolution is expected in IT field. Of course, the question is, are we ready for it?

Manufacturers can benefit by providing tablet devices with the most sought after features and requirements. Innovations in personal computer technology are a major stimulus for the overall economic growth. However, fast advancement in technology quickly replaces the existing one. A question may be raised whether a technological innovation is just a fad. Is it worthwhile to invest in a fad? Therefore, companies must plan in which technology to invest. When existing technology is rapidly replaced, there is little support for them. Therefore, it is imperative to study the appropriate technology to invest considering the interest of a larger market (Eizenberg, 2014).

There is a high risk in introducing innovative products, and accurate targeting is warranted. For this purpose, consumer perception is extremely important. Researchers have identified various factors that affect consumer attitude towards technology. Many models have been proposed to determine the correct attitude concerning technology.

The aim of this study was to determine which factors affect adoption of tablet device in Pakistani market so that manufacturers and marketers can develop and introduce tablet devices based on the country context. Among the factors to study, income level affect was a major factor. By developing and introducing tablet devices based on Pakistan's consumer needs, the tablet industry is likely to be more efficient. Introducing a new technology carries many risks; both monetary and non-monetary, requiring that the payoff be evaluated beforehand. By identifying the factors that impose the maximum influence on consumer behavior of a market, better return can be assured as marketers will bring tablets that are more in demand.

Tablet device is a new technology from Pakistani context. With its unique size and multiple mobility options, general public in Pakistan is hesitant to experiment with its usage. Pakistani people consider tablet device adopters belong to elite class. Since most of the Pakistanis belong to middle and low income group this view has been accepted as true. However, this judgment has a flaw as non-users view are only based on rumors and do not have any valid reason. Input from actual adopters is a must to actually know why people adopt tablet device. 
In this study, I endeavored to identify important factors affecting the attitude towards adoption of the tablet device. Our focus is on adoption of tablet technology. I did not want to introduce a bias for any particular brand in adoption of a technology. Apart from general factors, I specifically wanted to determine whether income status had any effect on its adoption.

The tablet computer market is expected to become the third largest consumer market in the electronics sector. It will grow to $\$ 49$ billion business by 2015 worldwide (Pakistantoday, 2011). It has been suggested that tablet device is generally preferred for middle and higher income groups. Huawei has taken the initiative to introduce cheap but high quality and innovative tablets. Earlier research conducted determined that Pakistan and Middle East markets will grow 39\% till 2014 for tablet device. Huawei is competing in price factor as it considers price a very important factor. India has demonstrated that price can significantly affect penetration of tablet devices by introducing their cheaper versions. However, the literature suggests there are other psychological and physiological factors that also affect consumer attitude towards tablet (Davis, 1989; Venkatesh \& Morris, 2000). These findings prompted us to test other factors as well.

The Research objectives are:

a) To determine important factors having effect on adoption of the tablet device, and

b) To determine the impact of income level on adoption of tablet device.

\section{Literature}

Formal introduction of tablet devices came in 1989(Warkentin, Bekkering, Schmidt, \& Johnston, 2004). However, they were limited to niche markets until 2002 when Microsoft introduced commercial tablet PC. The stimulus for introduction of tablet device was the concept of detachable keyboard.(Ozok, 2008).

Tablets allow multi-tasking. Tablets are operable while doing activities such as eating, an airline travel or doing laundry. Tablets are used to send email to news shows and looking up company information while simultaneously watching investment programs(McClard \& Somers, 2000).

In a report published by Oh et al. (2011), tablet usage was compared with e-reader and Smartphone. It was found that tablets were used most extensively while watching TV, whereas the e-reader had maximum usage when people were in bed. Smartphone has maximum usage when people are with friends or waiting for someone. Most people also use Smartphone more commonly compared to tablet and e-reader in bathroom. However, it was found tablet had more usability in class and meeting environments. Most people preferred working on Smartphone while commuting compared to tablet and e-reader (Wells et al., 2013). Jongepier (2011) found that battery life and processing speed were important to consumers when considering smart phones. In his view, new technologies such as smartphone allow users to be more productive, entertained in new ways and communicate more freely.

An important part of a computing device is software. Although not tangible, yet it is the main element that brings a computing device to life. Today software giants are running the scene. Apple and Google constitute the single main reason for the success of the tablet technology. Apple attaches so much importance to the software side that it channels all software through its own trusted application store. It has been found tablets are not used much for text intensive activities due to inadequate text input methods. Based on research, very few people use tablets on a desk. An ideal tablet should have an integrated keyboard, which should be removable as well. Consumers usually prefer a larger screen of 10 inches for tablets as it allows more comfortable viewing of websites. The ideal tablet will allow internet access from everywhere; however, they are neither designed for nor meant to replace personal computers. It is possible that in time people will be able to adapt to tablets so that they do not need PCs at all except in formal office settings. Therefore, it can be concluded tablets are used in a different way 
than a PC (McClard \& Somers, 2000). Tablets are highly appropriate for note taking and in field jobs in which mobile computing is essential (Berque et al., 2004). A new generation of tablet devices is around the corner with the introduction of Samsung galaxy note 10.0. This tablet has been specially designed by the manufacturer to allow tablet user to cross the barrier of content creation. It has a new input tool trade marked as $\mathrm{S}$ pen with which precise editing of images is possible. These tablets are intended to be almost as powerful as computers (Samsung galaxy note, 2013).

Earlier tablets were considered fun medium appropriate for casual emailing, chatting, web surfing and note taking. However, presently tablets are being developed with functionality in mind. They can be used to conduct small conferences (Ozok, 2008) and come with mobile capability. SMS is a feature that has been found to be effectively used to learn languages (Levy \& Kennedy, 2005) and literature(Bollen et al., 2004). SMS provides support, motivation, continuity, alerts, reminders and tips (Kukulska-Hulme \& Traxler, 2005). Tablets allow seamless integration of mobile and laptop, and provide a welcome combination of functionalities earlier provided by mobile, camera, GPS and computer (Sharples, 2003). The current line of tablets is highly appealing to tech-savvy users due to the media-rich environment (Corbeil, 2007).

According to a classification of mobile technologies by Naismith et al. (2004), Tablet PC is in first quadrant. Devices in the first quadrant are characterized by portability and personal use. We can note tablet device in between PDA and Laptop as proposed way back in 2004 and is still valid. Tablet has a mix of features present in laptop and PDA. Some of the features that differentiate a tablet from a PDA are a larger screen size of around 7-11 inches. Secondly, tablet devices are meant for office and entertainment purpose. PDA is more of a dedicated device for field work. Laptop has a unique characteristic of being almost similar to desktop PC except this that it has battery that allows laptop to operate for one to three hours without household power supply - an important feature from the perspective of frequent load shedding in Pakistan. The tablet itself has many variations. For example some similar products are notebook, netbook, sub-notebook and e reader. Tablet is available as a slate or convertible model. Ipad and Samsung galaxy tablet are of slate type. Slate type has no keyboard. Convertible has fixed keyboard, which can be adjusted to hide keyboard completely (French, 2007). Example of convertible tablet is Microsoft windows based tablet PC that arrived in market in late 2002 such as Lenovo X61 (Tablet computer, 2013). The smaller version of tablet PC is known as ultramobile PC. They have a touch screen of 7 inches. They are equally expensive as 10 inch full sized Tablet PC. Feature wise they are usually same(Corbeil, 2007).

Technology acceptance has been studied by numerous models. Each model had its advantageous and disadvantageous. One model does not fit all scenarios. Therefore, IT and consumer adoption models were reviewed. Therefore, I reviewed models related to IT and consumer adoption field. First study on technology acceptance was done by Davis (1989). He proposed technology acceptance model (TAM), which has been verified, re-examined, improved and expanded multiple times to include factors relevant to current technological developments (Koufaris, 2002; Venkatesh et al., 2000). TAM has two independent variables, perceived ease of use and perceived usefulness. They combine to effect behavioral intention. Behavioral intention affects actual system usage (Davis, 1989). TAM is based on the theory of reasoned action. Ajzen and Fishbein (1973) proposed actual behavior was determined by behavioral intentions which are formed by attitude.

One more variant of TAM is the theory of planned behavior (TPB) (Ajzen \& Fishbein, 1973; Valois et al., 1988). TPB states attitude and perceived behavior control are the main factors affecting behavioral intention. TPB has also considered subjective norms. Perceived behavioral control was an added antecedent of behavioral intention and behavior in TPB. Combined TAM and TPB combines factors of TPB with perceived usefulness present in TAM to provide the fused model (Taylor and Todd, 1995). The motivational model was proposed by Vallerand (1997). Davis (1993) used this theory to understand new technology adoption and use. This model considered extrinsic motivation and intrinsic motivation. 
In model of PC utilization, Thompson et al., (1991) tried to calculate user behavior. Its main factors were job fit, complexity, long-term consequences, and affects towards use, social factors and facilitating conditions. Innovation diffusion theory (Rogers Everett, 1995) has been in use since the sixties to study a variety of agricultural tools and organizational innovations. (Moore \& Benbasat, 1991) modified innovation diffusion theory to study individual technology acceptance. He found the modified model valid for these innovations. One important variable was image, which meant the amount to which an innovation is expected to enhance one's image in society. Social cognitive theory (SCT) is a very powerful theory. Compeau and Higgins (1995) stretched SCT in computer utilization context. However, they studied performance rather than adoption. Therefore, it can be concluded a single model is not applicable for every kind of research.

Venkatesh et al. (2003) proposed unified use of acceptance and use of technology, UTAUT model incorporated factors from all the previous eight models discussed above. It had four core independent factors, and four moderators. This model has significant linkage to our study. It includes factors that are expected to have significant effect on consumer behavior to adopt technological breakthrough such as tablet device. The four core independent factors are performance expectancy, effort expectancy, social influence and facilitating conditions. The moderators are gender, age, experience and voluntariness of use. The original TAM model included intention and attitude. Davis later revised the model and removed attitude and only kept intention. In his view, this model was stronger than the original one with attitude construct. A study by Anderson and Schwager (2006) UTAUT model along with four additional variables. Gender was found to have significant impact along with age, experience and voluntariness. An interesting study finding by Monroe (1973) shows that women are price conscious whereas men are feature conscious. Men are more concerned with perceived usefulness whereas women are more concerned with the perceived ease of use (Venkatesh et al., 2003). A study by (Daud et al., 2011) shows that users have a resistance to technological change. Therefore, there should be ease of usage with every innovation. Perceived usefulness and satisfaction were also variables considered critical for mobile commerce usage.

Price has been found to be positively related to quality. Similarly, price has been found to be related to prestige. Some consumers go for costly products just to be recognized as big spenders. So consumers just do not spend more expecting more features but also for prestige and better quality (Lichtenstein, 1993). Men are found to be directly influenced by their attitude towards technology (Venkatesh \& Morris, 2000). However, females are more influenced by subjective norms. Subjective norms include peer and superiors' influence (Taylor \& Todd, 1995). In "A study of consumer behavior of mp4 payers" author Wang, Rau, and Salvendy (2011) found enjoyment was the most important factor for electronic gadgets such as mp4 player. The second was price. Author states price should be within reach of consumer. Age was shown to have negative relationship with consumer behavior. Enjoyment was found to be a major factor since mp4 players fall into entertainment industry.

According to Nielsen's U.S. Mobile Snapshot (2010), most of the consumers of new technology are aged between 18 and 34. (Tai \& Tam, 1997) conducted a study to identify life style of females in China. Buying behavior does not only depend on income level. Family orientation, home orientation, Brand consciousness, price consciousness, self-confidence, addiction to work, health consciousness and environmental consciousness were also found significant. Many wealthy middle aged women and men do not use expensive gadgets because of the presence of young children at home. Xpeira $Z$ by Sony has been manufactured with such people in mind being water and dust proof. If this capability is brought to tablet devices, more adoption of tablet devices is expected (Gaikar, 2013). Waqas (2008) confirmed TAM model is highly reliable in Pakistan's context. However his field of study was broadband internet. He found perceived usefulness and perceived ease of use had significant effect on attitude. An important consideration while choosing a model is to consider whether we can collect reliable data for the factors. For this reason, a simple model was considered as a base and then relevant factors were added. In addition, some factors were made constant. TAM is one of the most basic models with only two determining factors. However, TAM has been capable of predicting to a very high accuracy. 
Numerous researchers have added factors in TAM to conduct study in particular field. For example, Dholakia et al. (2004) presented an extended version of TAM. This model is known as TAM 2. It includes numerous factors to represent social influence and value perceptions. It has elements such as entertainment value, social enhancement, and desires to express voluntary system usage. However, it turned out to be very much extended and not useful in most cases. Similarly, Wu et al. (2007) extended TAM using the theory of self-efficacy and innovation attributes. This model also has too many variables for which getting reliable input is cumbersome. Liao et al. (2008) incorporated perceived enjoyment because their study was to evaluate consumer's personality while using 3-G services. They found perceived enjoyment having more significant effect than perceived usefulness and ease of use. Therefore, it can be concluded a base model is just a starting point. A researcher must identify factors that are relevant to his study. Nysveen et al. (2005) also stretched TAM to include relevant factors so that intention to use mobile chat services can be identified. It was found expressiveness was more important for male users and enjoyment was more important for female users.

Some other factors added to TAM were computer playfulness (Moon \& Kim, 2001), product involvement and perceived enjoyment (Koufaris, 2002). Demographic traits of a sample also need to be considered. As the technology has become more complex so has the adoption behavior. Therefore, factors relevant for one society are not necessarily relevant for other societies. The technology itself is a determining factor. Therefore, understanding of tablet device is also necessary to identify which factors are relevant for adoption behavior by consumer. Tablet device has been studied by previous researcher in organizational environment. However, those studies date back to 2002. In addition, acceptance of the tablet in those organizations was involuntary. Our research focuses on voluntary adoption by Pakistan's educated youth. As previous research has identified, young generation has the highest chance of adopting new technology so I have chosen to conduct our study on comparative youngsters. Research has also identified technological marvels such as tablet device requiring significant computer knowledge. Therefore, I will be conducting our study on university level students. They are heavy users of technology as well. Youngsters by nature are curious, wanting to experience new things and having everything on their fingertips.

While designing model for research, we examined various studies to get an understanding of factors that may affect our dependent variable. Just identifying the relevant factors is not enough. Operationalizing the factors is also an important part. Therefore, after preliminary finalization of the factors that I would include in our model for testing, I went through further studies to find items that can enable us to measure the factors adequately (Davis, 1989; Lai \& Chang, 2011; Venkatesh et al., 2003). To measure perceived usefulness and perceived ease of use, items were chosen from Davis (1989) and Lai and Chang (2011). Items for facilitation condition were found in an article "User acceptance of information technology: toward a unified view" by (Venkatesh et al., 2003). Although facilitation condition has not been studied as rigorously as perceived usefulness and perceived ease of use, still it appears extremely relevant to our society. Most people in Pakistan are risk aversive. To cover up risk, consumers look for facilities such as expert users who can advise them on what is the best option in terms of price and low maintenance. Similarly, most Pakistanis are not proficient in IT. Therefore, they look for people who can assist them in resolving hardware and software issues in their electronic gadgets.

To measure perceived price, items were chosen from thesis "Consumer behavior for mp4 player" by Natali. Price perception is considered very important from Pakistani point of view. Pakistan is characterized by a mix of very poor and very rich people. However the ratio of poor is significantly higher than the rich. As stated earlier, there is a mixed view regarding price perception. Some people are concerned about low price due to income issues. Then there are some people who actually want to spend more because they want to associate themselves with the elite class who have money to spend on expensive items. This is especially true for branded products such as Apple's line of iphones and Ipads. Items for attitude were found from an article "User acceptance of information technology: toward a unified view" by Venkatesh et al. (2003). Attitude has been measured in numerous studies. It 
has been found to be affected in numerous ways. In certain cases, it acts as an independent factor. In our study, attitude has been operationalized as a dependent variable. It is the main variable of interest.

\section{Methodology}

This study has used primary data collected first hand by researchers. A structured questionnaire was used to obtain the correct responses from the university students belonging to both the private and public education sectors. The study has been limited to universities operating in Islamabad city due to two reasons. Firstly, university students are heavy users of tablet device. Therefore, it is expected we can get the required optimal amount of responses in available time. Secondly, due to limited resources it was feasible only to conduct study within the city. Most Pakistanis are neither willing to tell nor aware of their true income level, so using public and private universities as indicators of income level seemed a feasible option. We intentionally chose three universities belonging to the public sector and three universities belonging to the private sector so that results were not biased to only one particular university within each sector.

Systematic sampling method is used since our respondents must have personally used a tablet device. This condition was set because non-users of tablet device could not honestly express experience of tablet device. Most of the features on tablet device are unique. A user of smartphone or laptop cannot explain experience of tablet device. Among these universities, students were randomly distributed questionnaires. 1000 questionnaires were distributed from which we received 972; twenty two questionnaires were having major missing values so they were separated from analysis. Twenty five respondents were found outliers during data screening; by this sample used in this study is 925 .

There are four independent variables. They are operationalized by means of items.

\subsection{Independent variables are as under}

\section{Facilitation condition}

It has been studied by Venkatesh et al. (2003). In their view, facilitation conditions are important for older people. Anderson (2006) found facilitation conditions were insignificant in his research. I would like to see what results we get in this study.

\section{Perceived price}

Natali (2008) found in his research that people want a price that they can afford. He could not say for sure whether low prices have a positive effect on attitude to adopt a technology.

\section{Perceived usefulness}

The degree to which a person believes that using a particular system would enhance his or her job performance (Davis, 1989).

\section{Perceived ease of use}

The degree to which a person believes that using a particular system would be free from effort (Davis, 1989). Perceived ease of use has been found to have significant effect on attitude. It has been tested.

\section{Attitude}

Attitude is the main dependent variable. It denotes the mind-set of how consumers think, feel, reason, and select between different alternatives (Davis, 1989). Attitude has a very strong association with the intention to perform some act. In Davis's model, attitude and intention have been used as separate variables. 


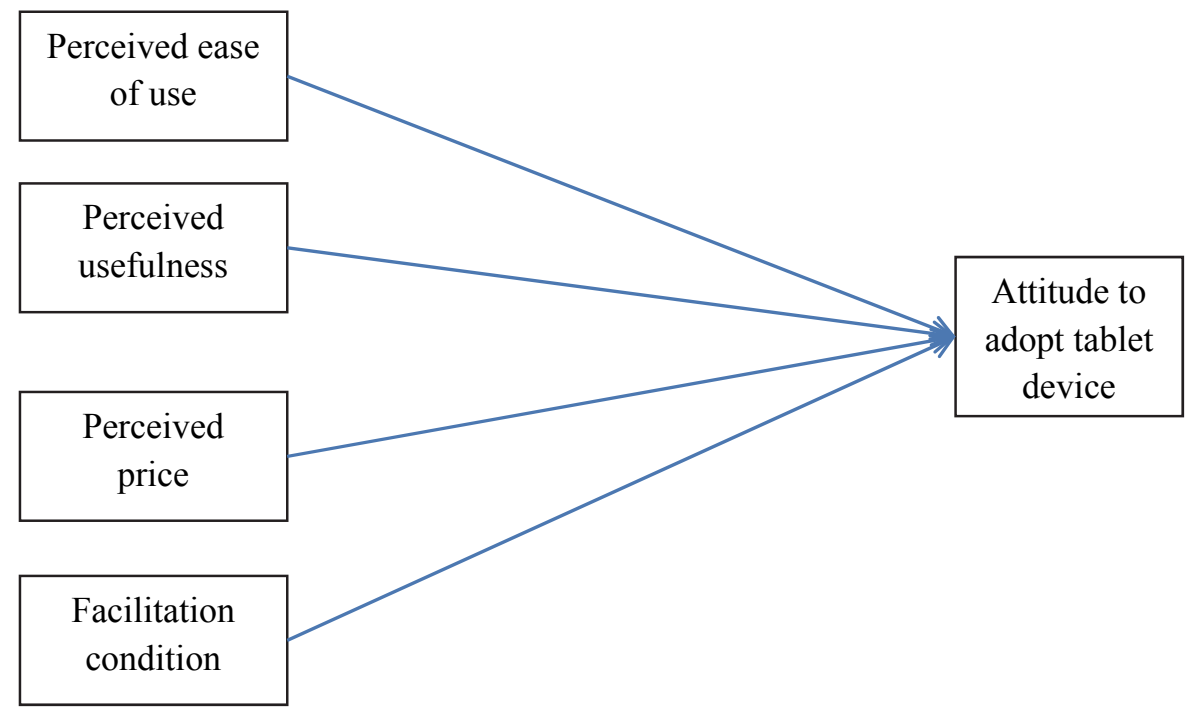

Independent variable

Dependent variable

Fig. 1. Proposed Model

\section{Hypothesis}

H1: The facilitation condition has positive effect on attitude to adopt tablet device.

H2: The perceived price has negative effect on attitude to adopt tablet device.

H3: The perceived ease of use has positive effect on attitude to adopt tablet device.

H4: The perceived usefulness has positive effect on attitude to adopt tablet device.

\section{Results and Discussion}

The data is analyzed through SPSS 18 version. First EFA was run to confirm the scale adoptability within our culture and social conditions. Principal component method was used with Varimax with Kaiser Normalization rotation while running EFA. Kaiser-Meyer-Olkin Measure of Sampling Adequacy is 83 per cent and items were found at their own variable except three items. One was from AATD variable "I like working with tablet device." While other two were from PEU variable they are "Becoming familiar with tablet device is easy, it is easy to get tablet device to do what one wants it to do." These three items were separated from further analysis as they were having cross loading with other variables. The retained items as per their variable are given in table number one. The reliability is checked through composite reliability and Cronbach's Alpha method. The composite reliability is given in the table number two, while as per Cronbach's Alpha AATD has $83 \%$, PU has $80 \%$, PEU has $70 \%$, PP has $69 \%$, and FC has 72 per cent reliability per variable. Validation of any factor analysis result is essential, particularly when attempting to define underlying structure among the variables. Validation involves assessing the degree of generalizability of the results to the population. The issue of generalizability is especially relevant for factor analysis because it describes a data structure that should be representative of the population as well. AVE is the Average Variance Extracted which tells about the convergent validity. The convergent validity refers to the adequacy with which a measure or scale has sampled from the intended universe or domain of content. The cut of value for AVE should be .50 but it can be accepted till .45 (Hair et al., 2010). In this case factor AATD has .54, PU has .54, FC has 62, PEU has .60 and PP has .50 AVE. 
Table 1

Rotated Component Matrix

\begin{tabular}{|c|c|c|c|c|c|}
\hline & AATD & $\mathrm{PU}$ & $\mathrm{PC}$ & PEU & PP \\
\hline I have the possibility to buy tablet device. & 0.76 & & & & \\
\hline Tablet device usage makes work more interesting. & 0.75 & & & & \\
\hline Working with the tablet device is fun. & 0.73 & & & & \\
\hline I can easily recommend buying tablet device to others. & 0.70 & & & & \\
\hline Using the tablet device gives a feeling of being in touch with modern computing technology. & 0.70 & & & & \\
\hline There is increase in easiness to conduct job by using tablet device. & & 0.78 & & & \\
\hline Using tablet device for work enhances my work effectiveness. & & 0.74 & & & \\
\hline There is increase in speed of completing task by using tablet device. & & 0.72 & & & \\
\hline There is increase in productivity by using tablet device. & & 0.72 & & & \\
\hline Using tablet device for work improves my work performance. & & 0.68 & & & \\
\hline There is guidance available while purchasing tablet device. & & & 0.82 & & \\
\hline There is support available to assist you with tablet device in case of hardware problems. & & & 0.80 & & \\
\hline There is support available to assist you with tablet device in case of software problems. & & & 0.74 & & \\
\hline Little effort is required to become skilful at using tablet device. & & & & 0.80 & \\
\hline I have clarity and understand ability of features available in tablet device to get things done. & & & & 0.78 & \\
\hline I feel comfortable to use tablet device in-terms of mobility. & & & & 0.73 & \\
\hline Price of branded tablet device is affordable to me. & & & & & 0.81 \\
\hline Price of used branded tablet device is affordable to me. & & & & & 0.69 \\
\hline Price of unbranded tablet device is affordable to me. & & & & & 0.59 \\
\hline
\end{tabular}

MSV is the Maximum Shared Squared Variance, and ASV is the Average Shared Squared Variance, both are the part of Discriminant Validity. Discriminant Validity extent to which a construct is truly distinct from other constructs both in terms of how much it correlates with other constructs and how distinctly measured variables represent only this single construct. Hair et al. (2010) discusses that MSV $<\mathrm{AVE} \& \mathrm{ASV}<\mathrm{AVE}$, as per our findings of this case are the same; it is given in table number two.

Table 2

Reliability and Validity

\begin{tabular}{lrrrr}
\hline Variable & CR & AVE & MSV & ASV \\
\hline AATD & 0.85 & 0.54 & 0.13 & 0.09 \\
PU & 0.85 & 0.54 & 0.12 & 0.06 \\
FC & 0.83 & 0.62 & 0.03 & 0.02 \\
PEU & 0.82 & 0.6 & 0.08 & 0.03 \\
PP & 0.74 & 0.5 & 0.13 & 0.05 \\
\hline
\end{tabular}

$\overline{\mathrm{CR}}=$ Composite Reliability; AVE $=$ Average Variance Extracted; MSV = Maximum Shared Variance; ASV= Average Shared Variance

The correlations between all variables are significant at the 0.01 level except the PP with FC. All correlation values and their mean and standard deviation is given in table number three. The proposed hypotheses are tested through multiple regression. Regression is run on the retained EFA extracted factors. Four hypotheses were proposed in this study. All hypotheses have been accepted. The H1 is "The facilitation condition has positive affect on attitude to adopt tablet device" has been accepted with $\mathrm{p}$ value 0.00 and its beta value is 0.122 . A second hypothesis is "The perceived price has negative affect on attitude to adopt tablet device" has been accepted with the $\mathrm{p}$ value 0.00 ; its beta value is 0.291 .

Table 3

Correlations Table

\begin{tabular}{lrrrrrrr}
\hline & \multicolumn{1}{c}{ Mean } & \multicolumn{1}{c}{ SD } & \multicolumn{1}{c}{ AATD } & PU & FC & PEU & PP \\
\hline AATD & 3.683 & 0.81577 & 1 & & & \\
PU & 3.5457 & 0.8387 & $.346^{* *}$ & 1 & & \\
FC & 3.36 & 0.94993 & $.187^{* *}$ & $.186^{* *}$ & 1 & 1 \\
PEU & 3.7705 & 0.70849 & $.286^{* *}$ & $.097^{* *}$ & $.115^{* *}$ & $.088^{* *}$ & 1 \\
\hline PP & 3.1446 & 0.84594 & $.367^{* *}$ & $.252^{* *}$ & -0.01 & .08 \\
\hline
\end{tabular}

**. Correlation is significant at the 0.01 level (2-tailed). 
Third hypothesis is "The perceived ease of use has positive affect on attitude to adopt tablet device" is also accepted with $\mathrm{p}$ value 0.00 and its beta value is 0.224 . The last hypothesis is "The perceived usefulness has positive affect on attitude to adopt tablet device" is accepted with the p value 0.00 and its beta value is 0.229 . The $\mathrm{R}^{2}$ is 27 per cent with $\mathrm{F}$ statistics 86.328 . The model is as well fit with the $\mathrm{P}$ value 0.000 .

Table 4

Regression Analysis Table

\begin{tabular}{lccc}
\hline Variables & \multicolumn{3}{c}{ Standardized Coefficients } \\
\cline { 2 - 4 } & \multicolumn{1}{c}{$\mathrm{t}$} & Sig. \\
\hline (Constant) & $\beta$ & 4.024 & 0 \\
PU & & 7.707 & 0 \\
FC & 0.229 & 4.236 & 0 \\
PEU & 0.122 & 7.888 & 0 \\
PP & 0.224 & 9.965 & $\mathrm{P} \leq .000$ \\
\hline $\mathrm{R}^{2}$ & 0.291 & $\mathrm{~F}=86.328$ & \\
Adjusted R $^{2}$ & 0.273 & & \\
\hline
\end{tabular}

a. Dependent Variable: AATD

\section{Conclusion}

This study explains the factors affecting adaptation behaviour for tablet device among completer users in Pakistan. The study is conducted at Islamabad which is the capital of Pakistan. The universities were selected with the concern to have equal representation because of this three public and three private universities were selected. This study contains 925 sample size. The literature was explored to propose the model. The proposed model is accepted and all hypotheses has been accepted, which manifest that tablet market is increasing in Pakistan besides that perceived price has the negative effect on the adoption behaviour of tablet device, which is having the more impact on the model than other variables. Pakistani market is price conscious which is also disclosed from this study results. Perceived ease of has second most impact on the adoption behaviour of tablet device while facilitation conditions have the least impact on the adaptation behaviour.

\section{Future Research and Limitations}

This research has been conducted with a sample from only six universities. A larger mix of universities was not possible due to resource and time constraints. However, the sample was fairly representative and sufficient to depict the position in private and public universities adequately. Effect of type of tablets has not been completely studied. Most of the consumers in Pakistan consider Ipad different from other tablet devices as it is associated with an extremely high brand power of Apple incorporation. Similarly, this study did not bring age as a factor. Age was contained by conducting study on youth. Earlier researchers have found that age acts as a moderator. Our study focused on adoption of tablet technology. Therefore, we did not bring brand as a factor. Generally, new technology is brought by powerful brands especially when research in current times requires lot of investment. In case new company does bring new technology, they use support of well-established brands. This study only provides insight about the Islamabad market and that too of a relatively small market segment. Although this segment is a heavy user of tablet device, future researchers may like to investigate the behavioural patterns and attitudes in larger segments. For example, research should be carried out in schools and corporations. Future research can be performed in organizational setup such as corporation. Research can be performed at school level. Research can be executed on a particular type of tablet. Facilitation conditions can be reanalysed while using age and gender as moderator. Perceived price can be rechecked while using brand as a moderating variable. Research should be replicated in other cities of Pakistan. A study should be done to elicit response from tablet owners so that effect of buying behaviour can be found. A qualitative study should be done to know what consumers want from a tablet device. 


\section{References}

Ajzen, I., \& Fishbein, M. (1973). Attitudinal and normative variables as predictors of specific behavior. Journal of personality and Social Psychology, 27(1), 41.

Anderson, J., \& Schwager, P. (2006). The Tablet PC: Applying the UTAUT Model. Paper presented at the American Conference on Information Systems, Acapulco, Mexico.

Anderson, J. E., Schwager, P. H., \& Kerns, R. L. (2006). The drivers for acceptance of tablet PCs by faculty in a college of business. Journal of Information Systems Education, 17(4), 429.

Berque, D., Bonebright, T., \& Whitesell, M. (2004). Using pen-based computers across the computer science curriculum. Paper presented at the ACM SIGCSE Bulletin.

Bollen, L., Eimler, S., \& Hoppe, H. U. (2004). SMS-based discussions-technology enhanced collaboration for a literature course. Paper presented at the Wireless and Mobile Technologies in Education, 2004. Proceedings. The 2nd IEEE International Workshop on.

Compeau, D. R., \& Higgins, C. A. (1995). Computer self-efficacy: Development of a measure and initial test. MIS quarterly, 189-211.

Corbeil, M. E. V.-C. (2007). ARE YOU READY FOR MOBILE LEARNING? Educausa Quarterly.

Daud, N. M., Mohamed, I. S., Alghanim, S., \& Alhamali, R. (2011). Revisiting Information System Models in the Context of Technology Usage and Technology Resistance. Australian Journal of Basic \& Applied Sciences, 5(12).

Davis, F. D. (1989). Perceived usefulness, perceived ease of use, and user acceptance of information technology. MIS quarterly, 319-340.

Davis, F. D. (1993). User acceptance of information technology: system characteristics, user perceptions and behavioral impacts. International Journal of Man-machine Studies, 38(3), 475-487.

Dholakia, R. R., Dholakia, N., \& Kshetri, N. (2004). Gender and Internet usage. The internet encyclopedia.

Eizenberg, A. (2014). Upstream Innovation and Product Variety in the US Home PC Market*. The Review of Economic Studies, rdu004.

French, J. H. (2007). Beyounf the tablet PC- using the tablet PC in a collaborative learning environment.

Gaikar, V. (2013). Sony Xperia Z Ultra Vs Galaxy Note 2.

Halme, O. (2011). E-reading devices as a new medium for newspaper reading.

Henderson, S., \& Yeow, J. (2012). iPad in education: A case study of iPad adoption and use in a primary school. 45th Hawaii International Conference on.

Jongepier, J. (2011). Young adopters of Smartphones (Doctoral dissertation, Erasmus University Rotterdam, The Netherlands).

Koufaris, M. (2002). Applying the technology acceptance model and flow theory to online consumer behavior. Information Systems Research, 13(2), 205-223.

Kukulska-Hulme, A., \& Traxler, J. (2005). Mobile learning: A handbook for educators and trainers: Psychology Press.

Lai, J.-Y., \& Chang, C.-Y. (2011). User attitudes toward dedicated e-book readers for reading: The effects of convenience, compatibility and media richness. Online Information Review, 35(4), 558580 .

Levy, M., \& Kennedy, C. (2005). Learning Italian via mobile SMS. Mobile learning: A handbook for educators and trainers, 76-83.

Liao, C.-H., Tsou, C.-W., \& Shu, Y.-C. (2008). The Roles of Perceived Enjoyment and Price Perception. International Journal of Business and Information, 3(1).

Lichtenstein, N. M. R. a. R. G. N. (1993). Price Perceptions and Consumer Shopping Behavior: A Field Study. Journal of Marketing Research, 30(2), 234-246

McClard, A., \& Somers, P. (2000). Unleashed: Web tablet integration into the home. Paper presented at the Proceedings of the SIGCHI conference on Human factors in computing systems.

Monroe, K. B. (1973). Buyers' subjective perceptions of price. Journal of Marketing Research, 70-80.

Moon, J.-W., \& Kim, Y.-G. (2001). Extending the TAM for a World-Wide-Web context. Information \& Management, 38(4), 217-230. 
Moore, G. C., \& Benbasat, I. (1991). Development of an instrument to measure the perceptions of adopting an information technology innovation. Information Systems Research, 2(3), 192-222.

Naismith, L., Sharples, M., Vavoula, G., \& Lonsdale, P. (2004). Literature review in mobile technologies and learning.

Nysveen, H., Pedersen, P. E., \& Thorbjørnsen, H. (2005). Intentions to use mobile services: antecedents and cross-service comparisons. Journal of the Academy of Marketing Science, 33(3), 330-346.

Oh, H.-Y., Min, B.-W., \& Oh, Y.-S. (2011). An improvement of mobile web interface design optimized for tablet PC environment Convergence and Hybrid Information Technology (pp. 770-777): Springer.

Ozok, A. A., Benson, D., Chakraborty, J., \& Norcio, A. F. (2008). A comparative study between tablet and laptop PCs: User satisfaction and preferences. International Journal of human-computer interaction, 24(3), 329-352.

Rogers Everett, M. (1995). Diffusion of innovations. New York.

Sharples, R. B. (2003). A technical review of mobile computational devices.

Tai, S. H., \& Tam, J. L. (1997). A lifestyle analysis of female consumers in greater China. Psychology and Marketing, 14(3), 287-307.

Taylor, S., \& Todd, P. A. (1995). Understanding information technology usage: a test of competing models. Information Systems Research, 6(2), 144-176.

Thompson, R. L., Higgins, C. A., \& Howell, J. M. (1991). Personal computing: toward a conceptual model of utilization. MIS Quarterly, 15(1), 125-143.

Vallerand, R. J. (1997). Toward a hierarchical model of intrinsic and extrinsic motivation.

Valois, P., Desharnais, R., \& Godin, G. (1988). A comparison of the Fishbein and Ajzen and the Triandis attitudinal models for the prediction of exercise intention and behavior. Journal of Behavioral Medicine, 11(5), 459-472.

Venkatesh, Morris, M. G., Davis, G. B., \& Davis, F. D. (2003). User acceptance of information technology: Toward a unified view. MIS quarterly, 27(3), 425-478.

Venkatesh, V., \& Morris, M. G. (2000). Why don't men ever stop to ask for directions? Gender, social influence, and their role in technology acceptance and usage behavior. MIS quarterly, 24(1), 115139.

Venkatesh, V., Morris, M. G., \& Ackerman, P. L. (2000). A longitudinal field investigation of gender differences in individual technology adoption decision-making processes. Organizational Behavior and Human Decision Processes, 83(1), 33-60.

Wang, L., Rau, P.-L. P., \& Salvendy, G. (2011). Older Adults' Acceptance of Information Technology. Educational Gerontology, 37(12), 1081-1099.

Warkentin, M., Bekkering, E., Schmidt, M., \& Johnston, A. (2004). Proposed study of end-user perceptions regarding Tablet PCs. Paper presented at the Innovations Through Information Technology: 2004 Information Resources Management Association International Conference, New Orleans, Louisiana, USA, May 23-26, 2004.

Wells, T., Bailey, J., \& Link, M. (2013). Filling the void: gaining a better understanding of tablet-based surveys. Survey Practice, 6(1).

Wu, J.-H., Chen, Y.-C., \& Lin, L.-M. (2007). Empirical evaluation of the revised end user computing acceptance model. Computers in Human Behavior, 23(1), 162-174.

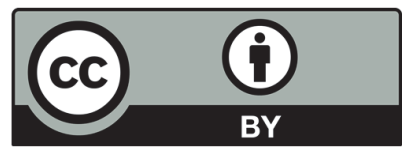

(C) 2016 by the authors; licensee Growing Science, Canada. This is an open access article distributed under the terms and conditions of the Creative Commons Attribution (CC-BY) license (http://creativecommons.org/licenses/by/4.0/). 